\title{
PROCESSOS INTERDISCURSIVOS EM LETRAS: LINGUAGENS E MÍDIAS NO PROCESSO DE INOVAÇÃO DA ÁREA
}

\section{INTERDISCURSIVE PROCESSES IN LINGUISTICS AND LITERARY STUDIES: LANGUAGES AND MEDIA IN THE INNOVATION PROCESS OF THE FIELD}

\section{Rogério Barbosa da Silva* \\ Wagner José Moreira}

RESUMO: Propõe-se uma breve reflexão sobre a interação entre as linguagens e mídias, resultando um estreito diálogo entre a linguagem e o tecnológico dentro de processos que recortam as esferas histórica, temporal, discursiva e audiovisual, especialmente nas poéticas interartes. Tais elementos têm constituído fundamentos da discussão realizada na disciplina Linguagem, Mídia e Processos Discursivos no âmbito no Mestrado em Estudos de Linguagens do CEFET-MG. PALAVRAS-CHAVE: Inovação. Linguagens e mídia. Imagem. Linguagem digital

ABSTRACT: We propose a brief reflection on the interaction between languages and media, resulting in a close dialogue between language and technological processes that underlie the historical, and temporal dimensions, but also discursive and audiovisual, especially

Professor de Literatura no Departamento de Linguagem e Tecnologia do Centro Federal de Educação Tecnológica de Minas Gerais (CEFET-MG). Doutor em Literatura Comparada pela UFMG. E-mail: rogeriobsilvacefet@gmail.com

** Professor de Literatura no Departamento de Linguagem e Tecnologia do Centro Federal de Educação Tecnológica de Minas Gerais. Doutor em Letras pela Pontifícia Universidade Católica de Minas Gerais. E-mail: wgnrjs@gmail.com 
in poetic interart. Such elements have formed the basis of the discussion held in the discipline Language, Media and Discourse Processes within the Postgraduate in Studies of Languages of CEFET-MG. KEYWORDS: Innovation. Languages and media. Image. Digital language 


\section{PROCESSOS INTERDISCURSIVOS EM LETRAS: LINGUAGENS E MÍDIAS NO PROCESSO DE INOVAÇÃO DA ÁREA}

Pensar a inovação tecnológica na área de letras tem-se tornado algo imperioso na medida em que, movido pela força de transformação das tecnologias de comunicação, todas as áreas de conhecimento são levadas também a pensar seus fundamentos e suas relações com o meio social. No entanto, não se deve ignorar que a palavra "inovação" vem sempre associada ao termo "tecnológico", que por estar sempre relacionado aos produtos de consumo num intenso ciclo de renovação, tende, em princípio, a conduzir-nos a noção de progresso e, por conseguinte, na obsolescência de tudo aquilo que antecedeu a determinada novidade tecnológica. Essa é, sem dúvida, uma conotação associada a uma perspectiva ingênua sobre a técnica. Aquela que, no contexto de uma explosão tecnológica e condicionada pela ausência de sensibilidade histórica, tende a absolutizar o presente, isto é, faz dele "o termo final do processo da realidade e deixa os acontecimentos e objetos que não viu nascer na penumbra onde relega tudo quanto não a impressiona diretamente." (PINTO, 2005: 233). São múltiplas as acepções de tecnologia, mas o mais importante é considerar a sua dimensão epistemológica como ciência dedicada ao estudo dos procedimentos técnicos e suas relações com o desenvolvimento civilizacional. Álvaro Vieira Pinto afirma que a "técnica é sempre um modo de ser, um existencial do homem, e se identifica com 
o movimento pelo qual realiza sua posição no mundo, transformando este último de acordo com o projeto que dela faz" (PINTO, 2005: 238).

Nesse sentido, é preciso reconhecer que o atual desenvolvimento das tecnologias de comunicação alterou substancialmente o regime e o fluxo de conhecimentos que perpassam as áreas e os saberes, tal como entende Alberto E. Maldonado ao afirmar que as tecnologias midiáticas

tornaram possível o início da estruturação de meios de comunicação subalternos com ampla distribuição de bens simbólicos. As produtoras radiofônicas, discográficas, televisivas, videotécnicas e editoriais produzem mensagens para milhões de pessoas paralelamente à mídia industrial e transnacional. O importante é que com a flexibilização produtiva, que as novas tecnologias permitem, já não é necessário montar uma indústria para gerar mensagens a milhões de pessoas; a pesar desse fenômeno estar ainda em estágios iniciais, a potencialidade das novas condições midiáticas manifestam-se como um fator crucial e estratégico de reformulação cultural.

(MALDONADO, 2003:3)

É nesse terreno que pretendemos situar as reflexões desse artigo que procura abordar nas enunciações discursivas as tensões postas pela relação linguagem/mídia, tendo em vista também a problemática da inovação no campo das letras.

Segundo Gómez, a palavra inovação surgiu e se alimentou da ideia de progresso social, consistindo em algo, ao mesmo tempo, mensurável e benéfico, em razão de seu valor agregado seja para o indivíduo ou para o antigo processo em face do qual se constitua o objeto de inovação (GÓMEZ, 2007: 210). Pergunta, portanto, em que as ciências humanas e as letras podem inovar? Diante dessa questão, o risco é sempre cairmos na velha armadilha da superioridade do técnico ante o teórico: Álvaro Vieira Pinto diz que o técnico costuma se situar como um benfeitor por haver desentranhado uma 
justa teoria na prática. Por sua vez, o teórico (seja ele filósofo ou sociólogo) termina por ser excluído, em razão de ser dotado de percepção crítica e por não estar alinhado com os sistemas de automação (Cf. PINTO, 2005: 232). É preciso, portanto, relativizar a noção de progresso, perceber, como demonstra Edgard Morin, que "todo progresso é parcial, local, provisório e, além disso, produz degradação, desorganização, isto é, regressão" (MORIN, 1986: 323). E ainda que "o pensamento tecnocrático só concebe o que é vivo, antropológico e social, segundo a lógica simplificadora das máquinas artificiais" (MORIN, 1986: 324). Pensar a inovação no campo das letras e das ciências humanas comporta, portanto, discutir as complexas relações que cercam os objetos do pensamento, no que tange às suas crises, evoluções, revoluções e regressões, tal como propõe Morin. Escapar aos idealismos embutidos no progresso das ciências, revelando as cegueiras produzidas por trás do discurso de elucidação, o qual elide os sujeitos e se esconde em meio à formalização tecnocrática e à hiperdisciplinaridade generalizante que envolvem as áreas de saber (Cf. MORIN, 1986: 325).

Então, se a percepção crítica é, por excelência, a ferramenta que dominamos nas áreas humanas, é com ela que podemos falar em inovação. É o sentido de inovação que permeia as relações que sujeitos e objetos reformulam o campo discursivo.

É nesse ó viés que a compreendemos nas reflexões em torno da disciplina Linguagem, Mídia e Processos Discursivos, ministrada no âmbito do Mestrado em Estudos de Linguagens do CEFET-MG. Tal como enfatizamos em nosso projeto de curso, a linguagem, a tecnologia e o discurso são compreendidos em um sentido amplo, abarcando os diferentes processos poéticos e semióticos com que o homem, agente de comunicação, de pensamento e de criação, está em contato cotidianamente. Ressalta-se que a convivência cultural e a complexidade das redes de informação moderna e contemporânea conduzem a uma reflexão sobre a sociedade como um agenciamento de forças que se efetivam no plano social, político e histórico. A partir dessa trama, as diversas formas de saber, como a ciência, a arte, a poesia e a narrativa, tratam a matéria para a composição de seus discursos.

Para tanto, buscamos, com Walter Benjamin, evidenciar uma perspectiva histórica que leve em conta a linguagem, entendida como instrumento que 
constrói o fato chamado historiográfico. Essa linguagem pode ser a verbal, a visual, a sonora ou os espaços de interseção estabelecidos pelo diálogo entre elas. Vale lembrar que a partir desse entendimento, deve-se perceber o princípio de que toda ação é histórica, prevalecendo nesse olhar o evento, assim como toda a experiência de linguagem determina o sujeito e a sua relação com o meio que ajuda a construir.

Essa noção de evento, implicando intersecção e mobilização pelo sujeito, aparece no fragmento intitulado "Teoria do Conhecimento" em Passagens, de Walter Benjamin. Ali, para justificar a tese de que o historiador deve construir uma estrutura filosófica, ao mesmo tempo sutil e resistente, o filósofo alemão evoca uma descrição de Sigfried Giedion, evidenciando ao final a necessidade de se ressignificar os artefatos produzidos pelo homem:

Nos degraus da Torre Eiffel, varridos pelo vento, ou melhor ainda, nas pernas de aço de uma pont transbordeur, confrontamo-nos com a experiência estética fundamental da arquitetura de hoje: através da fina rede de ferro estendida no ar, passa o fluxo das coisas - navios, mar, casas, mastros, paisagem, porto. Elas perdem sua forma delimitada: quando descemos, elas rodopiam umas nas outras, e simultaneamente se misturam'. Sigfried Giedion, Bauen in Frankreich, Leipzig-Berlim, p. 7. Assim também o historiador de hoje tem que construir uma estrutura - filosófica sutil, porém resistente, para capturar em sua rede os aspectos mais atuais do passado. No entanto, assim como as magníficas vistas das cidades oferecidas pelas novas construções de ferro - ver também as ilustrações 61-63 de Giedion - ficaram durante muito tempo reservadas exclusivamente aos operários e engenheiros, também o filósofo que deseja captar aqui suas primeiras visões deve ser um operário independente, livre de vertigens e, se necessário, solitário. (BENJAMIN, 2006: 501) 
Trata-se de uma passagem significativa justamente porque, sem deixar de render elogios aos artefatos tecnológicos produzidos pela inteligência, mostra-nos que o conhecimento deriva de uma construção do histórico; os artefatos não só retêm experiências e traços de uma técnica aprendida ao longo dos séculos, como também esses artefatos, ao se constituírem como ápices de uma nova etapa do desenvolvimento técnico, demandam também um reposicionamento crítico da parte do filósofo. A partir daí, Benjamin reivindica para o seu trabalho uma teoria próxima à ligada à montagem, uma "proposta metodológica para a dialética da história cultural", que consistiria em "estabelecer para cada época, em seus diferentes 'domínios', segundo determinados pontos de vista: de modo a ter, de um lado, a parte 'fértil', 'auspiciosa', 'viva' e ' positiva', e de outro, a parte inútil, atrasada e morta de cada época." (BENJAMIN, 2006, p. 501). Evidentemente, esse pensamento continua válido para a nossa época atual, em que vivemos a explosão tecnológica que remodela não só os processos nos vários campos da economia e da sociedade, quanto nos mantém cada vez mais prisioneiro dos dispositivos, os quais, por sua vez, expandem as potencialidades das redes de comunicação em âmbitos jamais vistos.

Uma segunda perspectiva que nos orienta é a temporal, a qual deve levar em conta o complexo subjetivo como um processo, seja para caracterizar uma identidade de caráter heterogêneo, seja para indiciar o modus operandi sociocultural vigente na atualidade. Aqui somos conduzidos pelas reflexões de Deleuze, Paul Virilio, Félix Guattari, Baudrillard, Vilém Flusser, entre outros, nas discussões sobre a imagem cinematográfica e televisiva, nos espaços da realidade virtual, no ato de imaginar propulsionado pelos aparelhos ante os modos de apropriação pelo sujeito, o que nos permite perceber também a instância da imagem como ato político e social. Com Deleuze, desmontam-se os clichês que revestem as imagens na chamada "Civilização da Imagem" (para Deleuze, a "civilização do clichê"), discutindo as descolagens do real produzidas pelos processos de semiose no cinema neorrealista italiano. Para isso, Deleuze mostra o surgimento de um novo regime de imagem com o neorrealismo: a "image-fato", associada a um real ambíguo e, portanto, distinta do real representado ou reproduzido. Ao contrário do que pensara a crítica marxista, que via nessas novas imagens 
um enfraquecimento das ações políticas em razão de uma visão "confusa" das novas imagens, Deleuze acentua o seu caráter de cinema político justamente por produzir com essas imagens o insuportável, o intolerável, que ele tributa como "parte do visionário". Com Bergson, Deleuze entende que, numa imagem, percebemos sempre menos, ou apenas aquilo que estamos interessados em perceber. Por conseguinte, na medida em que nossos esquemas sensório-motores se quebram, possibilita-se o aparecimento de um outro tipo de imagem:

uma imagem ótico-sonora pura, a imagem inteira e sem metáfora, que faz surgir a coisa em si mesma, literalmente, em seu excesso de horror ou de beleza, em seu caráter radical ou injustificável, pois ele não tem mais de ser ' justificada', como bem ou como mal... O ser da fábrica vem à tona, e já não se pode dizer ' afinal, as pessoas precisam trabalhar...' Pensei estar vendo condenados: a fábrica é uma prisão, a escola é uma prisão, literal e não metaforicamente. Não se faz suceder a imagem de uma prisão à de uma escola: seria indicar apenas uma semelhança, uma relação confusa entre duas imagens claras.

(DELEUZE, 2005: 31-32)

Por sua vez, Paul Virilio discute as perturbações provocadas pelo desdobramento da visão no que designa como "segunda ótica", isto é, aquela relacionada ao desenvolvimento das tecnologias de comunicação atuais e que tornam possível, por exemplo, a teleconferência em distantes rincões do planeta, ou das transmissões televisivas em tempo real. A essas imagens digitais, por ele designadas como "pequena ótica", tendem à superação da noção clássica de horizonte, ou da perspectiva geométrica, a que ele caracteriza como a "grande ótica". Essas perturbações afetam profundamente as nossas percepções, pois alteram a nossa percepção mesma do tempo: 
À iluminação direta do astro solar, que decompõe em dias distintos a atividade de nossos anos, acrescenta-se para nós, de agora em diante, a iluminação indireta, a luz de uma tecnologia que favorece uma espécie de desdobramento da personalidade do tempo: o tempo real de nossas atividades imediatas, onde agimos simultaneamente aqui e agora na grade de horários da emissão televisiva, em detrimento do aqui, ou seja, do espaço do lugar de encontro, como neste colóquio que se estabelece entre nós graças ao satélite, mas, paradoxalmente, em nenhum lugar do mundo...

(VIRILIO, 1993: 102-3)

Tanto nas questões levantadas por Paul Virilio quanto naquelas imagens analisadas por Deleuze se colocam a intermediação dos dispositivos ou de sistemas maquínicos produtores. Deleuze, por exemplo, considera o cinema como uma espécie psicomecânica, ou autômato espiritual, que se reflete em seu próprio conteúdo, em seus temas, situações e personagens. Um autômato que tem facetas complementares, sendo, por um lado, aquele que revela como o pensamento pensa e se pensa a si mesmo:

(...) é nesse sentido que Jean-Louis Schefer pode creditar o cinema de um gigante atrás de nossas cabeças, ludião, manequim ou máquina, homem mecânico e sem nascimento que põe o mundo em suspenso. Mas, por outro lado, o autômato é também autômato psicológico, que se não depende mais do exterior não é por seu autômato, mas porque foi despossuído de seu próprio pensamento, e obedece a uma impressão interna que se desenvolve em visões ou em ações rudimentares (do sonhador ao sonâmbulo, e inversamente, por intermédio da hipnose, da sugestão, da alucinação, da idéia fixa etc.)

(DELEUZE, 2005: 312) 
Na medida em que renuncia a imagem-movimento, o cinema, através do aperfeiçoamento de seus meios técnicos, faz nascer a imagem-tempo, um novo regime de imagem, em que o espaço surge do tempo (Cf. DELEUZE, 2005: 314).

No caso estudado por Paul Virilio, a possibilidade de conversão do sinal de transmissão em sinal digital cria a possibilidade da telepresença, ou mesmo da tele-existência e desperta uma questão que transcende os espaços lúdicos da arte. É que se suprime a distância e torna as imagens, e de certa forma a realidade, ubíqua. Põe o sujeito diante de um "presente intensivo" que elide a cronologia temporal em prol de um tempo cronoscópico: subexposto/exposto/superexposto (Cf. VIRILIO, 1993: 110). Resultam, então, questões para o sujeito contemporâneo: uma visão de superfície das relações geopolíticas, ausência de um ressentimento coletivo derivado do que Virilio chama de "ser do trajeto" e, por conseguinte,

dos diversos regimes de percepção do mundo que se sucederam ao longo dos séculos, regimes de visibilidade das aparências ligados à história das técnicas e das modalidades de deslocamento, das comunicações à distância, com a natureza da velocidade dos movimentos de transporte e de transmissão, engendrando uma transmutação da 'profundidade de campo' e, consequentemente, da espessura ótica do meio ambiente humano [...]"

(VIRILIO,1993: 107)

Não se observa nessas considerações de Virilio uma nostalgia com a perda da profundidade. O que se reivindica é postura diferente em relação às transformações impostas pelas técnicas, na busca de um outro modo de se resgatar a subjetividade. Para Flusser, por exemplo, a visão superficial é que é aventura. É porque a imaginação nova, surgida pelos processos de codificação dos aparelhos, leva-nos a uma desconfiança do (e ao desprezo pelo) nível ontológico "profundo". Na medida em que o imaginador pode, diferentemente do escriba, desprezar pontos e regras que os ordenam em 
imagens, é ao mesmo tempo condenado e emancipado da superficialidade pela opacidade do aparelho. É o que permite que suas criações ou recriações possam aparecer numa tela de dispositivo, e que se possam localizar o nível ontológico no qual as consciências do imaginador e do consumidor ao receberem essas imagens (Cf. FLUSSER, 2008: 43-5).

Também Guattari entende que não há sentido os homens desviarem-se das máquinas, porque, elas são ao final, formas hiperdesenvolvidas e hiperconcentradas de certos aspectos de sua própria subjetividade. Ressalta ainda o filósofo: "Nenhum campo de opinião, de pensamento, de imagem, de afectos, de narratividade pode, daqui para frente, ter a pretensão de escapar à influência invasiva da 'assistência por computador', dos bancos de dados, da telemática, etc." (GUATTARI, 1993: 177). Rechaçando os idealismos e os universalismos, Guattari mostra-nos a necessidade de nos apropriarmos desses equipamentos, desterritorializando e entrelaçando o que designa como vozes/vias fundamentais. São elas as vozes de poder (que cercam os conjuntos humanos, por coerção ou dominação panóptica), as vozes de saber (articulações de pragmáticas técnico-científicas e econômicas) e as vozes de auto-referência (desenvolvimento de uma subjetividade processual autofundadora de suas próprias coordenadas). (Cf. GUATTARI, 1993: 179). Intrincadas, essas vozes permitiriam a criação de novas territorialidades existenciais. A articulação dessas vozes possibilita, portanto, emancipar a subjetividade. Se ela deve ser construída para ser conquistada, não pode também ser reunida e manipulada por uma visão monoteísta. E se o Capital começa a se dissolver nessa polivocidade animista e maquínica, abre-se espaço para que velhas subjetividades associadas à resistência ao poder hegemônico se ergam também, produzindo uma espécie de virada (Cf. GUATTARI, 1993: 190).

Como se pôde verificar nessa rápida discussão sobre a perspectiva temporal que nos orienta, há igualmente uma perspectiva audiviovisual, que nos permite entrelaçar as matrizes da linguagem, tal como proposto por Lúcia Santaella (Cf. SANTAELLA, 2001), em que se verifica não só que todas as linguagens tendem ao hibridismo, como é possível analisar as projeções do visual sobre o verbal, o sonoro sobre o visual, e assim por diante. 
Reflete-se ainda nessas discussões a perspectiva discursiva, através da qual se permite pensar o objeto de pesquisa como uma política tecnológica, independente de sua natureza verbal ou audiovisual, e independentemente dos objetivos, sejam eles críticos, teóricos, de aplicação tecnológica ou educacional. Inserem-se as questões proporcionadas pela expansão da Internet e as sofisticadas formas de produção e consumo de textualidades construídas em bases hipertextuais e hipermidiáticas. Além de perturbarem as tradicionais formas de registro estável do pensamento, as textualidades eletrônicas abriram caminhos para uma escrita colaborativa, que põe em crise noções de autoria, questões econômicas associadas aos direitos autorais, enquanto possibilitam uma reinvenção de formas de leitura e de comunicação em geral. As formas hipertextuais e hipermidiática abrem todo um campo de reflexões no campo da educação, criam-se plataformas que comportam bibliotecas realmente gigantescas disponíveis num clique de mouse. Tudo isso é bem conhecido, certamente. Mas os seus efeitos ainda estão longe de ser compreendidos, e muitas vezes aceitos. É o caso ainda de se explorar no campo das letras as virtualidades da escrita produzidas por códigos digitais, o que altera tanto a produção como o consumo dos textos. Isso nos leva a evocar Flusser, quando pensa, ainda na década de 1980, o "leitor do futuro". Considerava o autor que a escrita digital alteraria o processo de leitura, saindo de certa passividade da escolha de fragmentos de uma linha preescrita, para uma associação ativa de ligações transversais entre os elementos de informação disponíveis, e que modificaria também a nossa consciência histórica, já que a transcodificação digital abole a cronologia e permite o acionamento simultâneo de informações. Por exemplo, não importaria tanto saber se Aristóteles vem antes de Newton, já que eles se sobrepõem num mundo digital:

"No sistema de 'Newton', por exemplo, a 'inércia' irá de encontro ao 'motivo' (Motiv) do sistema de 'Aristóteles', e o princípio de 'justiça' do sistema de 'Aristóteles' esbarrará na cadeia de causalidades do sistema de 'Newton'. O leitor poderá manipular ambos os sistemas 
armazenados de tal maneira que surgirão estágios intermediários dos quais o sistema de Aristóteles pode surgir do de Newton tanto quanto o sistema newtoniano, do de Aristóteles."

(FLUSSER, 2010: 168).

A argumentação acima se justifica uma vez que Flusser toma por base a codificação que cria o digital, ou seja, a linguagem matemática, que se considera a-histórica. O que se discute é o princípio da programação que envolveu a escrita tipográfica, e o que hoje envolve a programação computacional. Há que se perguntar se tudo é programável. Flusser entende que sempre se escreveu aos homens como se eles fossem máquinas, e que, portanto, a eles se prescreveram padrões de comportamentos. Seria então o caso de pensar quais são as consequências desse pensar que se instaura a partir dos códigos digitais, com os quais se completa o fim de um ciclo, já que são prescrições para as máquinas. Outra pergunta, em se tratando, da escrita hipertextual, questionar, como fez George Landow, em que sentido ocorre o empoderamento do sujeito na rede? Quem controla o texto?

O próprio Landow (2006) levanta exemplos vários para responder a essas questões, demonstrando as formas de controle, mas também as aberturas proporcionadas pelo hipertexto, através das políticas que lhe são inerentes em processos de democratização que trazem implicações políticas tanto para as instituições quanto para os indivíduos. As instituições são impulsionadas à mudança, na medida em que a rede se expande e afeta os modos de comunicação. Mesmo em situações em que instituições e governos tentam controlar o acesso, a estrutura anti-hierárquica e descentralizadora da rede impede o fluxo monolítico da informação, tal como exemplifica o próprio Landow, discutindo as tentativas de controle do governo Chinês. A expansão da rede afeta profundamente o campo da educação, conforme mostra Landow, demonstrando a crescente autonomia dos estudantes frente o peso das hierarquias e formalizações acadêmicas. Mas é sempre desejável uma postura crítica, como mostra o autor nessa relação que estabelece entre a "filosofia edificante" de Richard Rorty e a hipermídia: 
A hipermídia parece encarnar uma política verdadeiramente descentrada, ou multiplamente centrada, que parece ser o equivalente político da filosofia edificante de Richard Rorty, cujo propósito é «manter a conversa ao invés de encontrar a verdade objetiva ... O perigo que o discurso edificante tenta evitar é que algum vocabulário dado, de maneira que as pessoas possam vir a pensar em si, iluda-os a pensar que, a partir de agora, todo discurso poderia ser, ou deveria ser, o discurso normal.

(LANDOW, 2006: 344) ${ }^{1}$

Dadas as questões esboçadas muito rapidamente neste artigo, destacando que elas têm promovido, no âmbito da disciplina Linguagem, mídia e processos discursivos, reflexões que complementam as pesquisas em projetos diversos ligados a linhas do Programa de Pós-Graduação em Estudos de Linguagens do CEFET-MG. Considerando a multiplicidade de interesses e áreas de interseção que perpassam esses projetos, tais como a literatura, as artes, a linguística, a comunicação, o designer e a educação, entre os mais comuns, tais discussões auxiliam na travessia de zonas de interseção, em que as especialidades devem interagir. Assim, adensam-se perspectivas críticas que são também trazidas por outras disciplinas e pelas pesquisas específicas associadas aos projetos. Mas aqui busca-se uma reflexão em que, por exemplo, as indagações sobre as questões estéticas de uma obra de arte impliquem também uma reflexão sobre o suporte e sobre os meios de divulgação, ou ainda aqueles em que a pesquisa comporte, não só o estudo teórico, mas também a contrafação de criação ou de aplicação - no caso, um produto de arte ou uma plataforma de ensino, por exemplo. E é nesse contexto que entendemos também a inovação na área, isto é, na medida em que o fazer

1 Tradução literal de "Hypermedia seems to embody a truly decentered, or multiply centered, politics that seems the political equivalent of Richard Rorty's edifying philosophy whose purpose is ' to keep the conversation going rather than to find objective truth... The danger which edifying discourse tries to avert is that some given vocabulary, some way in which people might come to think of themselves, will deceive them into thinking that from now on all discourse could be, or should be, normal discourse". 
crítico se torna permeável não só às múltiplas linguagens, como ainda na medida em que o pensamento teórico desdobra-se também em poiesis.

\section{REFERÊNCIAS BIBLIOGRÁFICAS}

BENJAMIN, Walter. Teoria do Conhecimento, Teoria do Progresso. In: BENJAMIN, W. Passagens. Trad. Irene Aron, Cleonice Paes Barreto Mourão. Belo Horizonte: Editora da UFMG; São Paulo: Imprensa Oficial do Estado de São Paulo, 2006. p. 499 - 530.

DELEUZE, Gilles. A imagem-tempo. Trad. Eloísa de Araújo Ribeiro. São Paulo: Brasiliense, 2005.

FLUSSER, Vilém. O universo das imagens técnicas: elogio da superficialidade. São Paulo: Annablume, 2008.

FLUSSER, Vilém. A Escrita: há futuro para a escrita?. Trad. Murilo Jardelino da Costa. São Paulo: Annablume, 2010.

GÓMEZ, Guillermo Orozco. Podemos ser mais criativos ao adotarmos a inovação tecnológica em educação?. Uma proposta de comunicação. $M A$ TRIZES - Revista do Programa de Pós-Graduação em Ciências da Comunicação da USP. São Paulo: USP, v. 1, n. 1, p. 209-216, 2007. Disponível em: $<$ www.matrizes.usp.br/index.php/matrizes/article/download/37/59>. Acesso em: 01 ago de 2013.

GUATTARI, Félix. Da produção de subjetividade. In: PARENTE, André (Org.). Imagem-máquina: a era das tecnologias do virtual. Rio de Janeiro: Editora 34, 1993. p. 177-191.

LANDOW, G. P. The politics of Hypertext: Who controls the text?. In: LANDOW, G. P. Hypertext 3.0: Critical theory and new media in an era of glo- 
balization. Baltimore, Maryland: The Johns Hopkins University Press, 2006. p. 321-376.

MALDONADO, Alberto Efrendy. Práxis reflexiva comunicacional e configurações sociais transformadoras. Ciberlegenda - Revista do Programa de Pós-Graduação em Comunicação da UFF. Niterói: UFF, n.12, p. 1-11, 2003. Disponível em: <http://www.uff.br/mestcii/efendy4.htlm>. Acesso em: 01 ago. 2013.

MORIN, Edgar. Para sair do século XX. Trad. Vera de Azambuja Harvey. Rio de Janeiro: Nova Fronteira, 1986.

PINTO, Álvaro Vieira. O conceito de Tecnologia. Rio de Janeiro: Contraponto, 2005. (v. 1)

SANTAELLA, Lúcia. Matrizes da Linguagem e pensamento: sonora, visual, verbal. São Paulo: Iluminuras, 2001.

VIRILIO, Paul. O espaço crítico. Trad. Paulo Roberto Pires. Rio de Janeiro: Editora 34, 1993. 